\title{
Análise da comunicação entre cego e estudante de Enfermagem*
}

\author{
Analysis of communication between blind people and Nursing students \\ Análisis de la comunicación entre ciego y estudiante de Enfermería
}

\author{
Lorita Marlena Freitag Pagliuca', Cristiano Gil Regis', Inacia Sátiro Xavier de Françall \\ 'Universidade Federal do Ceará, Departamento de Enfermagem. Fortaleza, CE \\ "Universidade Estadual da Paraíba, Departamento de Enfermagem. João Pessoa, PB
}

Submissão: 04/05/2007

Aprovação: 10/0 1/2008

\section{RESUMO}

Análise da percepção de três duplas compostas por estudantes de Enfermagem videntes e por cegos sobre comunicação em interação livre filmada. Fundamentou-se na Análise de Discurso com dispositivo analítico constituído por entrevista após momento de comunicação e por conceitos próprios do referencial. O processo de análise trouxe à tona formações discursivas sobre comunicação, deficiência visual e inclusão social. Momento de comunicação avaliado positivamente, construindo paráfrases em seus discursos. Filmagem é fator de mudança emocional no início da interação dos estudantes de Enfermagem e indiferente para cegos. Provocou sentido no discurso de dois cegos e de uma estudante mediante silêncio fundador. Abre-se discussão sobre o tema e sobre a incorporação de novas tecnologias para a pesQuisa em Enfermagem.

Descritores: Enfermagem; Comunicação; Cegueira.

\section{ABSTRACT}

Analysis of how three duos of sighted Nursing students and blind people perceived communication in free recorded interaction. It was based on Discourse Analysis with an analytic tool constituted by an interview after the communication moment and by concepts characteristic of the reference framework. The analysis process revealed discourse formations about communication, visual impairment and social inclusion. The communication moment was assessed positively, constructing paraphrases in their discourse. Recording is a factor of emotional change at the start of the interaction for the Nursing students and blind people alike. It provoked meaning in the discourse of two blind persons and one student through founding silence. A discussion is started about the theme and about the incorporation of new technologies for Nursing research.

Descriptors: Nursing; Communication; Blindness.

\section{RESUMEN}

Análisis de la percepción de tres dúos compuestos por estudiantes de Enfermería videntes y por ciegos sobre comunicación en libre interacción grabada. Se basó en el Análisis de Discurso con dispositivo analítico constituido por entrevista tras el momento de comunicación y por conceptos propios del referencial. El proceso de análisis reveló formaciones discursivas sobre comunicación, deficiencia visual e inclusión social. Momento de comunicación evaluado positivamente, construyendo paráfrasis en sus discursos. Filmación es factor de cambio emocional al inicio de la interacción de los estudiantes de Enfermería e indiferente para ciegos. Provocó sentido en el discurso de dos ciegos y de una estudiante mediante silencio fundador. Se abre discusión sobre el tema y sobre la incorporación de nuevas tecnologías para la investigación en Enfermería.

Descriptores: Enfermería; Comunicación; Ceguera.

*Projeto financiado com recursos do Laboratório de Comunicação em Saúde/CNPQ e FUNCAP/MS.

Correspondência: Lorita Marlena Freitag Pagliuca. Universidade Federal do Ceará, Faculdade de Farmácia Odontologia e Enfermagem, Departamento de Enfermagem. Rua: Alexandre Baraúna, II 15. Rodolfo Teófilo. CEP 60430-I60 - Fortaleza, CE. 


\section{INTRODUÇÃO}

Deficiência visual é um termo empregado para referir-se à perda visual não corrigível com lentes por prescrição regular ${ }^{(1)}$. Esse termo é usado comumente tanto para a cegueira total como para a baixa visão.

Considera-se pessoa cega aeuela cuja visão corrigida do melhor dos seus olhos é de 20/200. Isto significa Que ela pode ver, a uma distância de 6 metros, um objeto Que uma pessoa de visão normal vê a 60 metros. Pode ser ainda aquela cujo diâmetro mais largo do seu campo visual não ultrapassa um arco superior a 20 graus. Já a pessoa com visão subnormal possui acuidade visual de 6/60 e 18/60 (escala métrica) e/ou um campo visual entre 20 graus e 50 graus $^{(2)}$.

Há várias causas de cegueira e de comprometimento visual. As mais comuns compreendem a degeneração macular, o glaucoma, a catarata, a retinopatia diabética, as doenças inflamatórias, os distúrbios genéticos e as lesões ${ }^{(3-4)}$.

De acordo com dados do Censo 2000 realizado pelo IBGE, no Brasil, existem 148 mil pessoas cegas e 2,4 milhões com grande dificuldade de enxergar ${ }^{(5)}$. Estimativas na população mundial de 1996 indicavam a existência de 45 milhões de indivíduos cegos e de 135 milhões com visão deficiente e risco de cegueira ${ }^{(6)}$.

Segundo se percebe, a relevância social da deficiência visual extrapola a esfera da saúde e atinge a sociedade como um todo, visto Que a pessoa com deficiência tem as mesmas necessidades das outras pessoas além das peculiares à sua condição. Em face dessas circunstâncias, os modos como o cego interage com o mundo, desenvolve suas atividades diárias e se comunica são diferentes e ocorrem conforme sua desenvoltura. Nesse contexto, a adaptação de indivíduos com deficiência visual congênita acontece na execução das atividades de vida diária por meio de mecanismos compensatórios no sistema de orientação. O custo de tal adaptação é alto e seus resultados são diversos, centrados nas potencialidades individuais, oportunidades de experiência e sucesso nas tarefas ${ }^{(7)}$.

Entre um cego de nascença e uma pessoa com comprometimento visual recente, existem diferenças significantes da comunicação. $\mathrm{O}$ fato de já ter enxergado pode ser traduzido em ganhos dos primeiros em relação aos segundos, , pois as características corporais como postura, gesticulação e meneio de cabeça são aprendidas durante a visualização. Desse modo, a comunicação está presente em todas as etapas da vida, é um elemento essencial para a socialização das pessoas e pode ter objetivos específicos ${ }^{(8)}$. Aparece em diferentes formas de interação interpessoal, grupal e social; é dinâmica, evolui, modifica-se, modificando-nos e modificando os outros ${ }^{(9)}$.

A comunicação, Quer seja a verbal ou a não-verbal|(10), lança mão da palavra falada e escrita e da expressão corporal e facial, respectivamente. Como uma forma de manifestação, as funções básicas da comunicação não-verbal são complementares à comunicação verbal. Ela pode substituir, contradizer e demonstrar ${ }^{(9)}$. Nesse processo, a comunicação entre o deficiente visual e o vidente pode ser comprometida, pois o deficiente visual, em virtude da sua condição, possui pobre resposta não-verbal, e este é um elemento Que reforça a comunicação do vidente. Ante tais limitações, a troca de informações inerente à comunicação pode não acontecer ou acontecer apenas parcialmente. Desse modo, forma-se uma barreira entre os dois comunicantes.

Essas barreiras dificultam a comunicação, sobretudo no atendimento a uma pessoa cega, o Qual deixa muito a desejar. Como exemplifica a experiência, existe um conjunto de fatores Que contribuem para essa realidade ainda pessimista. Pesquisas realizadas pela Enfermagem evidenciam dificuldades da comunicação verbal e não-verbal entre enfermeiro e paciente e ressaltam a necessidade de aprimorar técnicas Que melhorem a comunicação entre vidente e cego. Como dificuldade, menciona-se a própria formação profissional, ainda inabilitada para preparar o enfermeiro com vistas a desenvolver habilidades e intervir diante de uma pessoa com cegueira ${ }^{(1)}$. As enfermeiras mostram-se inseguras no relacionamento com deficientes e apresentam dificuldade de comunicação ${ }^{(12)}$.

A comunicação é essencial em QualQuer relacionamento e, sobretudo no do enfermeiro-cliente, o processo de comunicação precisa ser eficiente para viabilizar uma assistência humanística e personalizada de acordo com as necessidades da pessoa atendida ${ }^{(13)}$. Somente pela comunicação efetiva é Que o profissional poderá ajudar o paciente a perceber seus problemas, enfrentá-los, visualizar sua participação na experiência e encontrar alternativas de solução, além de auxiliá-lo a desenvolver novos padrões de comportamento $^{(14)}$.

A exemplo dos profissionais, também os estudantes de Enfermagem sentem dificuldades em manter comunicação com o cego. Seja por inexperiência ou por medo de não serem compreendidos, eles evitam prolongar as interações e muitas vezes transferem para outros essa responsabilidade. Se a situação acontece durante a fase na Qual o estudante experimenta os primeiros contatos com clientes, a comunicação pode ser inoperante. Tendo em vista esse aspecto, objetivou-se analisar como cegos e estudantes de Enfermagem videntes percebem a comunicação entre si, em uma situação de interação livre registrada em filmagem na perspectiva de interpretação do referencial teórico da Análise de Discurso.

\section{ANÁLISE DE DISCURSO COMO REFERENCIAL TEÓRICO-METODOLÓGICO}

A comunicação, como objeto de estudo, pode ser estudada de diferentes maneiras e teorias. Ao tomar a Análise de Discurso como dispositivo analítico, o pesquisador precisa ter em mente Que esse dispositivo não trata da língua, nem da gramática. Ela trata do discurso, da palavra em movimento, da língua fazendo sentido como trabalho simbólico Que constitui o homem e que se insere na história ${ }^{(15)}$.

Proceder a uma análise de discurso implica a desconstrução do texto em discursos, ou seja, em vozes. A técnica consiste em desmontar para perceber como foi montado ${ }^{(16)}$. Ela não trabalha com as marcas (formais), mas com propriedades discursivas (materiais) Que referem a língua à história (relação língua exterioridade). Marcas formais, em si, não interessam diretamente, e sim como elas aparecem no texto ${ }^{(15)}$.

Visa-se a compreensão de como um objeto simbólico produz sentido, como ele está investido de significância para e por sujeitos $^{(15)}$. Nessa passagem do sem-sentido para o sentido, a história não é pensada como fatos, e sim como processo simbólico, no Qual, em grande medida, nem sempre é a razão Que conta: inconsciente e ideologia aí significam ${ }^{(17)}$. O sentido depende das posições ideológicas daqueles Que empregam as palavras e do 
processo sócio-histórico em Que as palavras são produzidas. Partindo da idéia de que a materialidade específica da ideologia é o discurso e a materialidade específica do discurso é a língua, trabalha-se a relação língua - discurso - ideologia. Não há discurso sem sujeito e não há sujeito sem ideologia ${ }^{(15)}$.

Em face do dispositivo teórico da interpretação, há uma parte Que é da responsabilidade do analista e outra Que deriva da sua sustentação no rigor do método e no alcance teórico da Análise de Discurso $^{(15)}$. O analista não busca a verdade absoluta a partir da linguagem; ele interpreta o objeto discursivo a partir da materialidade histórica do sujeito.

Para a realização da análise, é preciso considerar a existência de dois esquecimentos, intitulados como número dois e número um, convencionalmente, descritos sempre nessa ordem, o segundo antes do primeiro. O esquecimento número dois, Que é da ordem da enunciação, explica Que, ao se falar, faz-se de uma maneira e não de outra, e, ao longo desse dizer, formam-se famílias parafrásticas Que indicam Que o dizer sempre podia ser outro. Explica-se assim por Que se diz certas palavras ao invés de outras. Ao se dizer "sem medo", poderia se usar "com coragem", ou "livremente" em seu lugar $^{(15)}$. Este é um esquecimento parcial e semiconsciente, pois, ao longo do discurso, pode-se voltar a esta margem de famílias parafrásticas para explicar melhor o Que foi dito.

O esquecimento número um, conhecido como ideológico, é da instância do inconsciente e resulta do modo pelo qual se é afetado pela ideologia. Por ele, tem-se a ilusão de ser a origem do Que se diz Quando, na realidade, retomam-se sentidos preexistentes ${ }^{(15)}$. Faz parte da necessidade do ser humano de sentir-se no início da linguagem, como se fosse o primeiro a dizer certas palavras significando o que realmente quer dizer. Entretanto, os sentidos já estão postos ou estão se construindo na história.

Um dos primeiros pontos a considerar, ao se pensar a análise, é a constituição do $\operatorname{corpus}^{(17)}$, Que está intimamente ligada com a análise. Decidir o Que faz parte do corpus já é decidir acerca de propriedades discursivas ${ }^{(15)}$. Na seção a seguir, apresenta-se detalhadamente o corpus.

\section{METODOLOGIA}

Estudo de caráter Qualitativo, exploratório e descritivo, realizado no Laboratório de Comunicação em Saúde (LabCom-Saúde) do Departamento de Enfermagem da Universidade Federal do Ceará (UFC), no mês de outubro de 2006.

O Laboratório, fruto de uma parceria entre o Departamento de Enfermagem da Universidade Federal do Ceará e a Escola de Enfermagem de Ribeirão Preto, com financiamento do CNPQ, é dividido em cinco ambientes: (1) Ante-sala, destinada a reuniões, espera e acomodação dos visitantes antes da atividade planejada; (2) Sala de filmagem, espaço amplo no Qual situações fictícias e reais de comunicação podem ser realizadas; (3) Aquário, onde se localizam equipamentos como computador, mesas de edição e controle das câmeras; (4) Banheiro; e (5) Copa.

Os sujeitos do estudo foram três cegos e três estudantes Que concordaram em fazer parte da peseuisa. Foram convidadas a participar apenas pessoas acima de 18 anos. Para seleção dos estudantes utilizou-se como critério a ausência de interação anterior com deficiente visual, seja ele cego ou de baixa visão. Para seleção dos cegos, entrou-se em contato com um grupo de deficientes visuais participantes do Projeto "Uso de computadores na educação de pessoas com deficiência visual" da Faculdade de Educação da UFC. A seleção aconteceu dentro do próprio grupo, por opção dos cegos.

Realizou-se uma vivência de comunicação entre estudantes de Enfermagem e cegos no interior do LabCom-Saúde: os sujeitos foram organizados por sorteio simples em três duplas, cada uma composta por um estudante de Enfermagem e um cego. Agendaramse encontros informais entre os dois membros de cada dupla. A data e o horário do encontro foram fixados pelo pesquisador e submetidos à aprovação dos participantes.

Após a experiência de comunicação entre os sujeitos no LabComSaúde, cada participante reuniu-se com o peseuisador para a realização da entrevista, iniciada pela Questão norteadora: "O Que você achou do momento de comunicação ocorrido?". Os sujeitos relataram para o pesQuisador a percepção da experiência vivenciada, como se sentiram durante a conversa e avaliaram a comunicação.

Inicialmente foram entrevistados os cegos e, em seguida, os estudantes. Nenhum dos sujeitos presenciou a entrevista do outro. Essas entrevistas foram documentadas por três câmeras filmadoras digitais assim dispostas: duas em suportes fixos às paredes acima do campo de visão dos sujeitos e uma sobre um tripé à altura deles e posicionada em frente ao entrevistado a uma distância de aproximadamente um metro e meio. $\mathrm{O}$ entrevistador não foi captado nesta filmagem.

Durante a filmagem o pesquisador e uma pessoa de apoio permaneceram dentro do Aquário de onde podiam observar a interação por meio de uma janela de vidro espelhada. Na sala de filmagem o ambiente era agradável e acolhedor, semelhante a uma sala de estar, contendo mesa, duas cadeiras, bandeja com copos, guardanapos, água, suco e bolachas. Os sujeitos foram esclarecidos sobre os procedimentos de registro do encontro, o Qual foi conduzido pelos próprios participantes e sem roteiro predeterminado. Nele, cego e acadêmico estabeleceram comunicação espontânea sobre tema do interesse de ambos. Explicou-se aos sujeitos Que podiam dispor do ambiente como bem Quisessem, servir-se dos alimentos e Que não havia lugar determinado para cada um deles se posicionar.

Em seguida, o corpus foi composto por materiais audiovisuais relativos às entrevistas contendo o discurso dos sujeitos da pesquisa em forma de entrevista. Para melhorar a dinâmica de trabalho, optou-se pela transcrição.

Como determinado, o projeto foi aprovado pelo Comitê de Ética em Pesquisa do Complexo Hospitalar da Universidade Federal do Ceará sob no 0039.0.040.000-06, respeitando as normas da Resolução 196/96 do Conselho Nacional de Saúde ${ }^{(18)}$. Após consentimento da instituição, providenciou-se a assinatura do Termo de Consentimento Livre e Esclarecido dos sujeitos do estudo. O termo foi lido para as pessoas cegas e todos os entrevistados foram esclarecidos sobre os objetivos do estudo, sendo-lhes garantidos o sigilo sobre as informações prestadas e o direito de desistir dele a Qualquer momento.

\section{RESULTADOS}

A maioria dos sujeitos da peseuisa pertence a uma privilegiada 
parcela da população por ter acesso à educação superior: além dos videntes, acadêmicos de Enfermagem, dois dos cegos também eram estudantes universitários. Esses últimos ingressaram na Universidade a partir de políticas inclusivas da própria instituição. Um deles cursa Psicologia e o outro Pedagogia. O terceiro sujeito era auxiliar de radiologia e trabalhava em um hospital público de referência da cidade.

As duplas constituídas pelos sujeitos apresentaram formações heterogêneas. A primeira interação durou aproximadamente 45 minutos e foi realizada por dois homens, o cego, Que tem 35 anos, é estudante de Pedagogia da UFC e ingressou na Universidade após iniciar participação no Projeto "Uso de computadores na educação de pessoas com deficiência visual", e o estudante de Enfermagem, 23 anos. O momento de comunicação ocorrido antes da entrevista tendeu para polissemia (discurso lúdico).

A segunda interação aconteceu em um período de tempo de meia hora. Nessa dupla, ambos os sujeitos eram do sexo feminino e tinham 22 anos. A pessoa cega cursava o $3^{\circ}$ semestre de Psicologia e ingressou na faculdade após conclusão do ensino médio. Considerou-se que a comunicação também tendeu para o discurso lúdico. Apesar da estudante de Enfermagem usar menos a palavra, a interação manteve características de polissemia em sua maioria.

Nesses dois primeiros casos, embora a polissemia tenha predominado, percebeu-se uma tendência ao discurso autoritário em alguns momentos, tendo como detentores da paráfrase os cegos.

A última interação durou Quarenta minutos e envolveu uma estudante de Enfermagem de 25 anos e um cego de 40 anos, casado e Que trabalha como auxiliar de radiologia em um hospital de referência da cidade. A comunicação teve características do discurso autoritário, e tendeu para paráfrases. Nessa interação, o sujeito cego sobressaiu em virtude de sua interlocutora não disputar o referente e assumir a postura de ouvinte.

Em todas as interações, o conteúdo predominante abrangeu a cegueira e as formas de convívio social com a deficiência visual, dando ao cego uma retomada maior às famílias parafrásticas. Ou seja: a produção de diferentes formulações do mesmo dizer sedimentado $^{(15)}$, exprimindo o mesmo discurso sobre haverem gostado de ter participado da pesquisa.

Contudo, precisa-se afastar a idéia de Que a avaliação positiva dos sujeitos não faz parte do silêncio local, Que é a censura, aQuilo Que é proibido dizer em certa conjuntura. Como houve silêncio local, aceitou-se a idéia de Que os sujeitos não estavam totalmente à vontade durante a entrevista. Um dos motivos para este comportamento poderia ser o receio imposto pelo entrevistador ou o interesse de manter uma postura de polidez para beneficiar a pesquisa. No entanto, tais hipóteses foram descartadas em face do rigor técnico usado pelo pesQuisador ao explicar aos sujeitos a forma de condução da pesQuisa, livre de relações de poder. Além disso, estabeleceu-se uma relação amigável entre os participantes e o pesquisador em decorrência dos inúmeros contatos mantidos para agendamento do encontro e orientações sobre o projeto.

Ao se observar o procedimento de análise no Qual utilizaram-se paráfrases (repetição) e metáfora (deslize), percebeu-se Que ocorreram repetição e deslocamento nos recortes citados: "Olha, foi bem interessante (Cegol)/ Foi uma experiência interessante (Cego3)/ Foi bem tranqüilo (Vidente2). Eu achei normal (Cego2)/ Achei bem interessante (Vidente I)/ Eu achei legal, gostei, assim, achei interessante (Vidente3)."

O termo "interessante" repete-se de forma redundante nos trechos em que os sujeitos analisam a interação, transferindo a ela o adjetivo: "(A interação, a experiência) foi interessante". Já "normal", "interessante" e "legal" se equivalem no segundo grupo de trechos pelo contexto a Que remetem.

Apesar da palavra "normal" designar uma postura de neutralidade, foi usada pela pessoa cega da segunda interação como silêncio constitutivo. Este silêncio aparece Quando uma palavra apaga outra. Ao dizer Que "foi normal", não disse Que "foi anormal, fora do comum". Considerou a interação como QualQuer outra Que acontecesse fora do universo da peseuisa, na rua, por exemplo.

Considere-se o esquecimento número dois, Que ilude ao se pensar que o que se disse só poderia ser dito daquela e não de outra forma. Ao superá-lo, pode-se chegar às famílias parafrásticas e encontram-se outras formas do dizer. As falas dos sujeitos expressando a percepção de cada um sobre o momento de comunicação anterior equivalem-se ao entender Que cada uma é uma alternativa diferente para dizer a outra. Confere-se então repetição, semelhança, no discurso dos sujeitos.

Outra Questão comentada, Que se torna o elemento especial da pesQuisa, é o uso de câmeras filmadoras para registrar os momentos de comunicação. Entretanto, apenas três sujeitos, dois estudantes e um cego, fizeram referência à filmagem. Os dois estudantes atribuíram características negativas ao seu uso por modificar seus estados emocionais. A repetição (paráfrase) é a forma como se posicionaram: "No início você fica um pouco tenso (Vidente I)/Eu (es)tava até nervosa (Vidente3)." Aqui, nervoso e tenso, como sinônimos, expressam a forma como se sentiram em relação à filmagem.

Quando o estudante da primeira interação diz: "No início você fica um pouco tenso", têm-se dois pressupostos. Primeiramente, é comum (aceitável) ficar tenso ou nervoso no início de uma filmagem. Em segundo lugar, se ele ficou tenso no início da interação, significa Que não estava assim antes da interação. Talvez o fato de já ter mantido momentos de comunicação semelhantes tivesse dado familiaridade à situação. Considere-se também que a pesquisa aconteceu dentro do Departamento de Enfermagem, local no Qual o estudante tem aulas e reuniões diariamente, mas o ambiente do LabCom-Saúde era novo para eles. Contudo, o nervosismo por adentrar em um local novo, desconhecido, não aparece aQui.

Posteriormente, o estudante diz: "Eu (es)tou sendo observado." Esta é a razão da tensão inicial do sujeito. Ao imaginar que a interação possuía observadores (câmeras e pesQuisador), o sujeito reproduz sensações universais, como um discurso que é esquecido e pode ser retomado por Qualeuer pessoa. Ao final, confirma Que o esQuecimento da existência de câmeras ao longo da conversa o fará agir naturalmente.

A estudante da terceira interação produz discurso semelhante (parafrástico), mas uma peculiaridade é notada. Quando ela diz: "Eu estava até nervosa", não se pode pressupor Que estava calma antes. O não-dito aparece agora como subentendido. Se ela estava nervosa, sabe-se Que em algum momento anterior esteve calma, mas não se pode afirmar Que foi no momento imediato que antecedeu o início da interação. Entretanto, a estudante diz: "Mas depois que eu comecei a conversar com ele eu fieuei calma, tranQüila," mostrando Que o estado de nervosismo não é uma constante e Que se sentiu 
tranqüila com o desenrolar do diálogo.

A única pessoa cega Que citou o uso de filmagem trouxe uma posição de neutralidade: "Normal. Como se não tivesse gravando (Cego2). " Para ela, a forma de registro da pes@uisa não interferiu na comunicação.

A ausência de comentários dos demais sujeitos a respeito da gravação em vídeo apresenta-se como silêncio fundador, Que faz com Que o dizer signifique. Não considerou-se como silêncio local, Que exprime censura, devido à forma livre como o pesQuisador conduziu a entrevista. O silêncio fundador produz sentidos ao ser posto frente ao dito. $\mathrm{O}$ uso de filmagens, visto como fator de estresse, não aparece no discurso de dois cegos e de uma vidente por não produzir interferência digna de nota. Quando se confronta esse silêncio com as falas Que avaliam positivamente a interação, percebe-se uma concordância de sentido. Este argumento é reforçado pelo discurso da pessoa cega Que afirmou não terem as câmeras alterado o andamento do encontro.

Os três sujeitos cegos convivem naturalmente com a constante observação unidirecional dos videntes em relação a eles por ser essa a peculiaridade da cegueira. Se a observação e o conseQüente julgamento dos videntes ocorrem em todas as esferas da vida, não seria no momento da pesquisa Que sentimentos de receio ou incômodo apareceriam.

Contudo, tal situação é diferente para os videntes, Que sabem exatamente o poder da imagem por terem a oportunidade de ocuparem ambas as posições. Na vida cotidiana, a visão é utilizada na comunicação não-verbal como troca de mensagens. Na pesQuisa, entretanto, os olhos das câmeras e do pesquisador, ocultos atrás de um espelho, causaram incômodo por não reproduzirem a situação real de poder observar o observador.

\section{DISCUSSÃO}

A opção de utilizar um recurso técnico para o registro da observação, por meio da filmagem, deu-se em razão da possibilidade de assistir ao fenômeno observado repetidas vezes ${ }^{(19)}$. Deu-se, também, para registrar o maior número de detalhes possíveis, pois são indiscutíveis as mudanças de comportamento pelas Quais a maioria das pessoas passa Quando estão sendo filmadas. Tem-se uma preocupação com a postura, a elocução verbal, os gestos e a aparência. A certeza de Que aquele momento será filmado e poderá ser visto inúmeras vezes por outrem estimula a pessoa a mostrar seu melhor lado, de passar boa impressão.

No entanto, Quando se trata de uma gravação extensa, as pessoas passam a agir naturalmente após algum tempo. Nesses casos, aos poucos o foco de atenção da pessoa se transfere da câmera para o Que está ocorrendo no momento. Se a situação filmada for uma conversação, por exemplo, o assunto discutido e a pessoa ou pessoas com Quem se conversa tornam-se mais importantes e a naturalidade esperada acontece.

Comumente a filmagem é utilizada para fins de vigilância em lojas, bancos, repartições públicas e condomínios, mesmo contrariando a vontade de pessoas que ao entrarem em um desses ambientes se deparam com a frase Sorria! Você está sendo filmado. O incômodo surge ao se pensar em Quem está observando a filmagem, Qual sua intenção e, acima de tudo, por Que é preciso sorrir? Esta última Questão remete ao já descrito neste trabalho, isto é, há uma preocupação com a estética pelos filmados. Essa frase largamente usada produz discurso de Que se a pessoa precisa passar pela gravação, mesmo forçadamente, Que o faça da melhor forma, sorrindo.

Essa idéia de vigilância, transportada para o âmbito da pesQuisa, dá sentido negativo à gravação audiovisual para registro. Mesmo após consentimento e esclarecimento das Questões éticas, os sujeitos videntes consideram a filmagem ponto modificador das próprias emoções (deixa-os nervosos) e dificultador do início da interação.

O discurso produzido em explicação à avaliação positiva do encontro define a interação produtiva e demonstra satisfação dos sujeitos em participarem da pesquisa. Durante os três encontros, todos com meia hora ou mais de duração, percebeu-se troca constante de mensagem com referente nítido e produção de sentidos. Enquanto o jogo de linguagem, característica do discurso tendencioso à polissemia, foi observado como dominante em duas situações, a injunção à paráfrase, presente no discurso autoritário, apareceu mais vezes no terceiro encontro.

No discurso lúdico, o referente está presente como tal, e os interlocutores se expõem aos efeitos dessa presença inteiramente, não regulando sua relação com os sentidos ${ }^{(20)}$. Difere do discurso autoritário em Que a polissemia é contida, o referente está apagado pela relação de linguagem Que se estabelece e o locutor se coloca como agente exclusivo, apagando também sua relação com o interlocutor ${ }^{(20)}$. Entretanto, a classificação dos discursos não deve ser confundida com a significação popular das palavras empregadas. Não se deve interpretar lúdico em relação a brinQuedo, mas a jogo de palavras, Que é a polissemia; nem fazer juízo de valor do sujeito pelo termo autoritário, pejorativamente, pois se relaciona com a Questão do fato simbólico, a injunção à paráfrase.

A presença constante do tema "deficiência visual" se deu pela curiosidade dos videntes sobre a vida social dos cegos. Ao terem os cegos alcançado objetivos como ingresso na Academia e profissionalização, romperam com antigos estereótipos e aproximaram-se da realidade inclusiva. É importante reconhecer aqui a força dos sujeitos cegos Que, em meio à sociedade predominantemente excludente, conseguiram ocupar posições de destaque. Assim, as condições de produção compreendem fundamentalmente os sujeitos e a situação. A memória também faz parte eneuanto interdiscurso, definido como aquilo Que fala antes, em outro lugar, independentemente. Ele torna possível dizer e retorna sob a forma do pré-construído, o já-dito que está na base do dizível, sustentando cada tomada de palavra ${ }^{(15)}$.

\section{CONSIDERAÇÕES FINAIS}

Como evidenciado, a análise das entrevistas por meio do modelo discursivo possibilitou a contextualização da deficiência visual, inclusão social e comunicação. Ademais, os sentidos produzidos via análise dos discursos dos sujeitos da pesQuisa promovem reflexão sobre a forma de lidar com a deficiência visual. A comunicação entre cego e estudante de Enfermagem vidente percebida por eles na formação do discurso descreve a ideologia de sujeitos conscientes de seus papéis na construção de marcas sóciohistóricas.

Quanto à utilização de filmagem, ao mesmo tempo em Que se 
caracteriza como recurso para registro de dados com inúmeros benefícios devido à sua fidedignidade, também compromete a espontaneidade dos sujeitos do estudo que refazem o sentido de seus discursos. A incorporação de formas diferentes do fazer mostra as inúmeras possibilidades a serem utilizadas para o alcance do objetivo final, mas há de se estar atento para interferências não desejadas.
Após a avaliação positiva da interação extraída do discurso, acredita-se que a comunicação estabelecida foi também considerada positiva pelos próprios sujeitos.

$\mathrm{Na}$ opinião dos autores, este trabalho vem colaborar com o arcabouço científico produzido na área da Comunicação em Enfermagem, e poderá servir de base para novas abordagens em estudos futuros.

\section{REFERÊNCIAS}

I. Moura GR, Pedro ENR. Adolescentes portadores de deficiência visual: percepções sobre sexualidade. Rev Latinoam Enfermagem 2006; 14(2): 220-6.

2. Whitcher IP. Cegueira. In: Vaughan DG, Asbury T, RiordanEva P. Oftalmologia Geral. 4ª ed. São Paulo (SP): Atheneu; 1997. p. 396-400.

3. Smeltzer SC, Bare BG. Brunner \& Suddarth: tratado de enfermagem médico-cirúrgica. 9a. ed. Rio de Janeiro (RJ): Guanabara Koogan; 2002.

4. Rim PHH, Magna LA, Ramalho AS. Genetics and prevention of blindness. ArQ Bras Oftalmol 2006; 69(4): 48 I-5.

5. Ministério da Saúde (BR). Conselho Nacional dos Direitos da Pessoa Portadora de Deficiência. Censo demográfico 2000: resultados da amostra características gerais da população, migração e deslocamento. Brasília (DF): Ministério da Saúde; 2003.

6. Temporini ER, Kara-José N. A perda da visão: estratégias de prevenção. ArQ Bras Oftalmol 2004; 67(4): 597-601.

7. Mauerberg-deCastro E, Paula AI, Tavares CP, Moraes R. Orientação espacial em adultos com deficiência visual: efeitos de um treinamento de navegação. Psicol: Reflexão Crítica 2004; 17(2): 199-210.

8. Pagliuca LMF. A arte da comunicação na ponta dos dedos - a pessoa cega. Rev Latino-am Enfermagem 1996; 4(esp): 127-37.

9. Paegle SO, Silva MIP. Comunicação não-verbal de pessoas portadoras de ostomias por câncer de intestino. Rev Bras Enfermagem 2003; 56(2): I30-32.

10. Stefanelli MC. Comunicação com o paciente: teoria e ensino. 2a. ed. São Paulo (SP): Robe; 1993.

11. Pagliuca LMF, coord. Acessibilidade da pessoa portadora de deficiência física e/ou sensorial aos serviços de saúde: estudo das condições físicas e de comunicação. Fortaleza (CE): Secretaria de Saúde do Estado do Ceará sobre projetos financiados pelo Ministério da Saúde. No prelo; 2007.

12. Pagliuca LMF, Fiúza NLG, Rebouças CBA. Aspectos da comunicação da enfermeira com deficiente auditivo. Rev Esc Enfermagem USP 2007; 4 I (3): 4 I I-8.

13. Oriá MOB, Moraes LMP, Victor JF. A comunicação como instrumento do enfermeiro para o cuidado emocional do cliente hospitalizado. Rev Eletr Enferm 2004; 6(2): 292-7.

14. Lopes CLR, Barbosa MA, Teixeira MEM, Coelho RB. A comunicação profissional de saúde $x$ cliente diante das novas tecnologias. Rev Bras Enferm 1998; 5 I (1): 53-62.

15. Orlandi EP. Análise de discurso: princípios e procedimentos. $3^{\text {a }}$. ed. Campinas (SP): Pontes; 2001.

16. Manhães E. Análise do discurso. In: Duarte J, Barros A, organizadores. Métodos e técnicas de pesquisa em comunicação. São Paulo (SP): Atlas; 2005. p. 306.

17. Orlandi EP. Vão surgindo sentidos. In: Orlandi EP, organizadores. Discurso fundador. $2^{\text {a }}$. ed. Campinas (SP): Pontes; 200I.p. I I-4.

18. Ministério da Saúde (BR). Conselho Nacional de Saúde. Diretrizes e normas regulamentadoras da pesquisa envolvendo seres humanos: Resolução no 196/96. Brasília (DF); 1996. [citado em II mar 2003]. Disponível em: URL: http:// www.ufrgs.br/hcpa/gppg/res 19696.htm.

19. Orlandi EP. A leitura e os leitores. Campinas (SP): Pontes; 1998.

20. Fujisawa DS, Manzini EJ. Formação acadêmica do fisioterapeuta: a utilização das atividades lúdicas nos atendimentos de crianças. Rev Bras Educ Especial 2006; 12 (1): 65-84. 